\title{
Polypharmacy and Related Factors in Geriatric Outpatients
}

\author{
(D) Pınar Küçükdağlı \\ istanbul University İstanbul Faculty of Medicine, Department of Internal Medicine, Division of Geriatrics, İstanbul, Turkey
}

\begin{abstract}
Objective: The term "polypharmacy" is defined as the usage of multiple medications or more medications than are clinically indicated. Older people tend to have several chronic diseases and prescriptions for these conditions. Polypharmacy is associated with significant consequences such as adverse drug reactions, medication nonadherence, drug-drug and drug-disease interactions, and increased risk of geriatric syndromes. The purpose of the present study was to evaluate the relationship between polypharmacy and common geriatric syndromes.
\end{abstract}

Materials and Methods: Three-hundred individuals $\geq 60$ years of age admitted to İstanbul Faculty of Medicine, Department of Geriatrics outpatient clinic between 2013-2016 were recruited to the study. Patients' data about the number of prescribed drugs, falls (in the preceding year), urinary incontinence, constipation, presence of malnutrition, sleep disorders and functionality were noted. Polypharmacy was defined as the usage of four or more medications.

Results: The study was consisted of $198(66.8 \%)$ women and $102(33.2 \%)$ men with mean age of $76.5 \pm 6.7$ years. The prevalence of polypharmacy was $82.7 \%$. Univariate and multivariate analysis were performed to examine the relationship between polypharmacy and other geriatric syndromes. In regression analysis, polypharmacy was found to be independently associated with sleep disorders [Odds ratio (OR): $2.21,95 \%$ Confidence interval (Cl): 1.15-4.24, $\mathrm{p}=0.016]$ and urinary incontinence (OR: $2.53,95 \% \mathrm{Cl}: 1.21-5.27, \mathrm{p}=0.013)$.

Conclusion: Polypharmacy is an important health problem among older adults, which is frequently associated with inappropriate medication use, increased risk of adverse drug reactions, and poor health outcomes. In this study, sleep disorders and urinary incontinence were found to be independently associated with polypharmacy. Clinicians should consider polypharmacy and related risks when prescribing medications for older adults.

Keywords: Polypharmacy, urinary incontinence, sleep disorders

\section{Introduction}

Polypharmacy, which is defined as the usage of multiple medications or more medications than clinically necessary, is a common health problem for older adults. Although there is no standard cut-off number of medications for the polypharmacy; it can be defined as the use of four or more medications (1).

Another definition is the administration of more medications than clinically indicated. Related to this definition, drugs not indicated for use, therapeutic duplications of medication should be considered as polypharmacy. Elderly population, represent nearly 42 million around the worldwide making up the 13.3\% of total population, are receiving more than $50 \%$ of all prescribed medications.
The number of drugs increases in relation to the multiple chronic conditions; such as diabetes mellitus, hypertension, chronic obstructive disease and heart failure. Polypharmacy is often required and appropriate in these cases.

Impaired function of organs and systems; such as heart, kidney, liver and stomach and adverse effects of drug metabolism appear with advancing age. Due to the changes in pharmacokinetic and pharmacodynamics of many drugs, the risk of adverse drug reactions increases. Response to drugs due to drug absorption, body distribution, metabolism, excretion and changes in receptor level show differences in elderly individuals. The prevelance of polypharmacy in the literature, ranges 5\% to $78 \%$, in relation to different definitions (2-5). Polypharmacy generally occurs due to demographic and health factors, and access to healthcare.

Address for Correspondence: Pınar Küçükdağlı, İstanbul University Faculty of Medicine, Department of Internal Medicine, Division of Geriatrics, İstanbul, Turkey

Phone: +90 5434369090 E-mail: pinarkucukdagli@hotmail.com ORCID: orcid.org/0000-0002-3632-8281

Received: Sep 22, 2019 Accepted: Sep 22, 2019

Cite this article as: Küçükdağlı P. Polypharmacy and Related Factors in Geriatric Outpatients. Eur J Geriatr Gerontol 2019;1(2):56-60

๑Copyright 2019 by the Academic Geriatrics Society / European Journal of Geriatrics and Gerontology published by Galenos Publishing House. 
Unfortunately, there are many negative outcomes; such as high expenses on healthcare, adverse drug events, drugdrug interactions, the increase at the risks of inappropriate medications, non-adherence to medication and geriatric syndromes associated with polypharmacy (6).

World Health Organization defined adverse drug events as "Unintended and undesired effects of a medication at a normal dose" and classified into five categories as adverse drug reaction, medication error, therapeutic failure, drug withdrawal and overdose (7-9).

In this study we aimed to examine the relationship between polypharmacy and common geriatric syndromes including falls, functionality, constipation, urinary incontinence, sleep disorders and malnutrition.

\section{Materials and Methods}

Three-hundred individuals $\geq 60$ years of age admitted to İstanbul University Faculty of Medicine, Department of Geriatrics outpatient clinic between 2013-2016 were included to the study. Patients' data on admission about the number of prescribed drugs, falls (in the preceding year), urinary incontinence, constipation, presence of malnutrition, sleep disorders, and functionality were evaluated by a geriatrician. Polypharmacy was defined as the use of four and more medications. Malnutrition was assessed by MNA-sf.

Presence of urinary incontinence, was defined as the unintentional loss of urine in the preceding year. Katz et al. (10) activities of daily living (ADL) scores and Lawton instrumental ADL (IADL) scores (11) were used to assess functionality. Patients were asked whether they have difficulty in sleeping; falling or staying asleep through the night. Insomnia is defined by a positive response to either question (12). Rapid eye movement behavior disorder was defined as clinically violent behaviour occuring during the night: sleep talking, vivid dreams, shouting, screaming, hitting or punching.

Patients were questioned about the presence of whitnessed sleep apnea, snoring, sweating, excessive daytime sleepiness or whether they had received a diagnosis of obstructive sleep apnea before. A simple questionnaire was used to define restless legs syndome (13). For ADL scores patients who got 6 points considered as dependent; and who got 18 points as independent; for IADL scores patients who got 8 points considered as dependent, and 24 points represented total independency. Constipation was defined as symptom based; combination of fewer than 3 stools per week, hard or lumpy form of stool, difficult stool passage for more than 6 month (14). The study protocol was approved by the İtanbul University Faculty of Medicine Ethics Committee on June 28, 2018 (number: 956).

\section{Statistics}

Variables were assessed whether normally distributed or not. Normally distributed numerical variables were presented as mean \pm standard deviation and non-normally (skewed) distributed variables were presented as median (minimummaximum). Frequencies were used to present categorical variables. For two groups comparison we used independent Sample t-test or Mann-Whitney U test. Correlations between categorical variables were analyzed with chi-square test. Pearson's or Spearman's rho correlation tests were used to analyze the correlation of numerical parameters. $P$ values less than 0.05 were accepted as statistically significant. We used Binary logistic regression models to investigate the relationship between variables and SPSS (statistical package for social sciences) version 21 program for statistical analysis.

\section{Results}

Among the three-hundred enrolled individuals, 198 (66\%) were women and $102(34 \%)$ were men. The mean age of the study population was $76.5 \pm 6.7$ (median 77 ) years, the mean number of chronic diseases was $4.19 \pm 2.1$ (median 4) and the mean number of medications was $7 \pm 2$ (median 7). The prevelance of four and more drug use was $82.7 \%$. The population of the study was tend to be more independent. The characteristics of study population are shown in Table 1.

Polypharmacy was found not to be associated with age or sex. Dependency in functionality (for ADL $p=023 /$ for IADL $p=0.045$ ), malnutrition $(p<0.001)$, urinary incontinence $(p=0.009)$, sleep disorders $(p=0.021)$ and falls $(p=0.028)$ were associated with polypharmacy.

In multivariate analysis, sleep disorders [Odds ratio (OR): 2.21, 95\% Confidence interval (CI): 1.15-4.24, $\mathrm{p}=0.016]$ and urinary incontinence (OR: 2.53, 95\% Cl: 1.21-5.27, $\mathrm{p}=0.013$ ) were independently associated with polypharmacy. Univariate and multivariate analysis' results are demonstrated in Table 2 and Table 3.

\section{Discussion}

The present study showed that, about $82 \%$ of patients have polypharmacy when we consider polypharmacy as the usage of four or more medications. The prevalence of polypharmacy varied between 5\% and 78\% in other studies reported from other countries (2-5). The heterogeneity in polypharmacy prevalence seems to be dependent on the development level of countries and the cut-off numbers of medications accepted as polypharmacy $(6,15,16)$. In this study; polypharmacy was not associated with age or sex.

Polypharmacy was independently associated with sleep disorders and the presence of urinary incontinence. 
Sleep disorders are common among older adults, because the aging process is associated with an increased risk of multimorbidity, polypharmacy, and psychosocial factors influencing sleep cycle. It is also associated with morbidity and mortality. In older adults using activating medications; insomnia symptoms are common. On the other hand, because

\begin{tabular}{|c|c|c|c|}
\hline & Total & Polypharmacy & $\begin{array}{c}\text { No } \\
\text { Polypharmacy }\end{array}$ \\
\hline Age (years) & $76.5 \pm 6.7$ & $78 \pm 5.8$ & $77.4 \pm 6.6$ \\
\hline \multicolumn{4}{|l|}{ Sex } \\
\hline Female $(\%)$ & $198(66)$ & $164(82.2)$ & $34(17)$ \\
\hline Male $(\%)$ & $102(34)$ & $82(80)$ & $18(17)$ \\
\hline Disease (chronic) & $4.2 \pm 2.1$ & $4.6 \pm 1.83$ & $7 \pm 1.9$ \\
\hline \multicolumn{4}{|c|}{ Functionality (ADL/IADL) } \\
\hline \multicolumn{4}{|l|}{ ADL } \\
\hline 0-6 (Dependent) & $1(0.3)$ & $1(0.3)$ & $0(0.0)$ \\
\hline 13-18 (Independent) & $292(97)$ & $242(80)$ & $50(17)$ \\
\hline \multicolumn{4}{|l|}{ IADL } \\
\hline 0-8 (Dependent) & $9(0.3)$ & $8(0.2)$ & $1(0.3)$ \\
\hline 17-24 (Independent) & $243(81)$ & $198(66)$ & $45(15)$ \\
\hline \multicolumn{4}{|l|}{ Nutrition (MNA-sf) } \\
\hline 0-7 (Malnutrition) & $14(4.6)$ & $12(4)$ & $2(0.6)$ \\
\hline$>11$ (Normal) & $223(74)$ & $179(59)$ & $44(14)$ \\
\hline Urinary incontinence & $140(47)$ & $124(42)$ & $16(5.4)$ \\
\hline Falls & $117(39)$ & $104(34)$ & $13(4.3)$ \\
\hline Constipation & $77(26)$ & $68(23)$ & $9(3)$ \\
\hline Sleep disorders & $141(47)$ & $124(42)$ & $17(5.7)$ \\
\hline \multicolumn{4}{|c|}{$\begin{array}{l}\text { "mean } \pm \text { standart deviation, number (\%)" } \\
\text { ADL: Activities of daily living, IADL: Instrumental activities of daily living, MNA-sf: Mini } \\
\text { Nutritional Assessment short form }\end{array}$} \\
\hline
\end{tabular}

\begin{tabular}{|c|c|c|c|}
\hline & p & OR & Cl $95 \%$ \\
\hline Gender & 1.0 & 1.03 & $0.55-1.93$ \\
\hline Age & 0.185 & 1.02 & $0.97-1.06$ \\
\hline Falls & 0.028 & 2.16 & $1.10-4.26$ \\
\hline Urinary incontinence & 0.009 & 2.34 & $1.23-4.44$ \\
\hline Sleep disorders & 0.021 & 2.14 & $1.14-4.03$ \\
\hline Malnutrition & $<0.001$ & 0.78 & 0.64-0.95 \\
\hline Constipation & 0.123 & 1.86 & $0.86-4.03$ \\
\hline$A D L$ & 0.023 & 0.95 & $0.88-1.02$ \\
\hline IADL & 0.045 & 0.87 & $0.67-1.12$ \\
\hline
\end{tabular}

ADL: Activities of daily living, IADL: Instrumental activities of daily living, OR: Odds ratio, $\mathrm{Cl}$ : Confidence interval of sedating medications, chronic illnesses or sleep apnea, patients may suffer from daytime drowsiness $(17,18)$.

Several medications commonly used in older patients, have various effects on sleep periods through multiple mechanisms. Antihistamines, anticholinergics and anticonvulsants, opiates are known to cause daytime drowsiness. Medications can have activating or stimulating effects on older adults, such as pseudoephedrine, beta agonists, corticosteroids, antidepressants or methylphenidate. Antidepressants can worsen restless leg syndrome and periodic limb movement symptoms, while opiates or benzodiazepins are known to exacerbate sleep disordered breathing.

Polypharmacy causes insomnia with a cascade effect like; many medications in relation to sleep disturbance and as a result of more medications required and prescribed $(19,20)$.

In a recent study, in 379 older patients, insomnia was found in $43 \%(n=163)$ and the mean number of medications was 9.2. No significant relation was found between insomnia and polypharmacy (21). In a study examining the association between the number and dosage of antipsychotic medications and sleep disorders, they found that the increased dosages of antipsychotics were associated with better sleep, although these medications were only associated with a relatively small amount of the variance in sleep quality.

Additionally, sleep complaints remained persistent in $70 \%$ of patients.

These results suggested that the use of antipsychotic medications have limited efficacy as a treatment option for sleep dysfunctions (22). In a recent study, aiming to evaluate the effects of the number of medications on the sleep periods, results showed that the number of medications had not effect on total sleep time but affected the sleep cycle negatively (23).

Urinary incontinence is one of the most common geriatric syndromes that is associated with the use of multiple medications and poor quality of life. Lower urinary tract symptoms increase with aging in both men and women, and constitute poor outcomes in older patients due to multiple medical and psychosocial conditions. Nuotio et al. (24) found that polypharmacy was associated with the increased risk of lower urinary tract symptoms in women aged 70 years or older.

Table 3. Multivariate analysis for factors associated with polypharmacy

\begin{tabular}{|l|c|c|c|}
\hline & $\mathbf{p}$ & $\mathbf{O R}$ & $\mathbf{C l} \% \mathbf{9 5}$ \\
\hline Sleep disorders & 0.016 & 2.217 & $1.157-4.248$ \\
\hline Urinary incontinence & 0.013 & 2.535 & $1.218-5.278$ \\
\hline $\begin{array}{l}\text { *Variables entered falls, malnutrition ADL, urinary incontinence, sleep disorders } \\
\text { ADL: Activities of daily living, OR: Odds ratio, Cl: Confidence interval }\end{array}$ \\
\hline
\end{tabular}


Many drugs are known to increase the risk of urinary incontinence and exacerbate the urinary tract symptoms such as diuretics, angiotensin converting enzymes, anticholinergics, opiates and calcium channel blockers. Clinicians should perform a medication review to evaluate the specific types and the number of medications (25).

In a recent study, examining the relationship between other geriatric syndromes and urinary incontinence; they found that mobility decline, polypharmacy, and pain were associated with urinary incontinence in both men and women. Delirium and fecal incontinence were associated with urinary incontinence in men, and cognitive impairment was significantly associated with urinary incontinence in women (26).

In a study evaluating the frequency of drugs that can exacerbate incontinence, prevalence of polypharmacy and adverse drug events in female patients with overactive bladder; researchers showed that $57 \%$ of the patients were using at least one drug that could exacerbate urinary incontinence. The prevalence of polypharmacy was 38\%, while $45 \%$ of the patients had drug-drug interactions that can disrupt the quality of life (27).

\section{Study Limitations}

The present study had some limitations. This is a retrospective study that contains no follow up data, and thus reveals no cause-effect relationship between polypharmacy and geriatric syndromes. The diagnosis of sleep disorders was based on a questionnaire and clinical suspicion; we did not any further evaluation. This study composed of community-dwelling outpatients' single center data; therefore the results can not be generalized.

However, this study also has some strengths. The total sample size was relatively large and patients were selected randomly from a large group of outpatients.

\section{Conclusion}

In this study, polypharmacy was independently associated with sleep disorders and urinary incontinence. These results indicated that patients, who suffered from sleep disorders and urinary incontinence, should be considered carefully in terms of the use of multiple medications. Healthcare practitioners should identify polypharmacy and patients at high risk for adverse outcomes associated with polypharmacy.

\section{Ethics}

Ethics Committee Approval: The study protocol was approved by the İstanbul University Faculty of Medicine Ethics Committee on June 28, 2018 (number: 956).

Informed Consent: This study is a retrospective study. Therefore, informed consent form was not taken.
Peer-review: Externally peer-reviewed.

Financial Disclosure: The author declared that this study received no financial support.

\section{References}

1. Bahat G, Tufan F, Akin S, Tufan A, Erten N, Karan MA. Rational Drug Use in the Elderly. J Gerontol Geriat Res 2012;1:104.

2. Fulton MM, Allen ER. Polypharmacy in the elderly: a literature review. J Am Acad Nurse Pract 2005;17:123-132.

3. Charlesworth CJ, Smit E, Lee DSH, Alramadhan F, Odden MC. Polypharmacy among adults aged 65 years and older in the United States: 1988-2010. J Gerontol A Biol Sci Med Sci 2015;70:989-995.

4. Hajjar ER, Cafiero AC, Hanlon JT. Polypharmacy in elderly patients. Am J Geriatr Pharmacother 2007;5:345-351.

5. Morin L, Johnell K, Laroche ML, Fastbom J, Wastesson JW. The epidemiology of polypharmacy in older adults: register-based prospective cohort study Clin Epidemiol 2018;10:289-298.

6. Shah BM, Hajjar ER. Polypharmacy, adverse drug reactions, and geriatric syndromes. Clin Geriatr Med 2012;28:173-186.

7. Kim J, Parish AL. Polypharmacy and Medication Management in Older Adults. Nurs Clin North Am 2017;52:457-468.

8. Conzelmann M, Breil D. [How to Manage Polypharmacy in the Elderly Praxis] (Bern 1994) 2016;105:509-516.

9. Cho CY, Alessi CA, Cho M, Andreas E. Stuck MD, Laurence Z. Rubenstein MD, MPH The Association Between Chronic Illness and Functional Change Among Participants in a Comprehensive Geriatric Assessment Program. J Am Geriatr Soc 1998;46:667-682.

10. Katz $\mathrm{S}$, Ford AB, Moskowitz RW, Jackson BA, Jaffe MW. Studies of illness in the aged. The Index of Adl: a standardized measure of biological and psychosocial function. JAMA 1963;185:914-919.

11. Lawton MP, Brody EM. Assessment of older people: self-management. Gerontologist 1969;9:179-186.

12. Roth T. Insomnia: Definition, Prevalence, Etiology, and Consequences. J Clin Sleep Med 2007;3(Suppl5):S7-S10.

13. Ferri R. Lanuzza B. Cosentino FI, Cosentino FI, lero I, Tripodi M, Spada RS, Toscano G, Marelli S, Arico D, Bella R, Hening WA, Zucconi M. A single question for the rapid screening of restless legs syndrome in the neurological $\neg$ clinical practice. Eur J Neurol 2007;14:1016-1021.

14. Paré $P$, Bridges $R$, Champion MC, Ganguli SC, Gray JR, Irvine EJ, Plourde $V_{\text {, }}$ Poitras P, Turnbull GK, Moayyedi P, Flook N, Collins SM. Recommendations on chronic constipation (including constipation associated with irritable bowel syndrome) treatment. Can J Gastroenterol 2007;21(Suppl B):3B-22B.

15. Midão L, Giardini A, Menditto E, Kardas P, Costa E. Polypharmacy prevalence among older adults based on the survey of health, ageing and retirement in Europe. Arch Gerontol Geriatr 2018;78:213-220.

16. Al Ameri MN, Makramalla E, Albur U, Kumar A, Rao P. Prevalence of Polypharmacy in the Elderly: Implications of Age, Gender, Co-morbidities and Drug Interactions. SOJ Pharm Sci 2014;1:1-7.

17. Bloom HG, Ahmed I, Alessi CA, Ancoli-Israel S, Buysse DJ, Kryger MH, Phillips BA, Thorpy MJ, Vitiello MV, Zee PC. Evidence-based recommendations for the assessment and management of sleep disorders in older persons. J Am Geriatr Soc 2009;57:761-789.

18. Ancoli-Israel S, Kripke DF, Klauber MR, Mason WJ, Fell R, Kaplan O. Sleepdisordered breathing in community-dwelling elderly. Sleep 1991;14:486-495.

19. Barczi SR, Teodorescu MC. Psychiatric and Medical Comorbidities and Effects of Medications in Older Adults. In: Kryger MH, Roth T, Dement WC (Eds). Principles and Practices of Sleep Medicine. 6th ed. Philadelphia, PA: Elsevier, 2016. 
20. Miner B, Kryger MH. Sleep in the aging population. Sleep Med Clin 2017;12:31-38.

21. Miner B, Gill TM, Yaggi HK, Redeker NS, Van Ness PH, Han L, Fragoso CAV Insomnia in Community-Living Persons with Advanced Age. J Am Geriatr Soc 2018;66:1592-1597.

22. Waters $F$, Faulkner $D$, Naik N, Rock D. Effects of polypharmacy on sleep in psychiatric inpatients. Schizophr Res 2012;139:225-228.

23. Lande RG, Gragnani C. Relationships between polypharmacy and the sleep cycle among active-duty service members. J Am Osteopath Assoc 2015;115:370-375.

24. Nuotio $M$, Jylhä $M$, Luukkaala $T$, Tammela TL. Health problems associated with lower urinary tract symptoms in older women. A population-based survey. Scand J Prim Health Care 2005;23:209-214.
25. Maher Jr RL, Hanlon JT, Hajjar ER. Clinical Consequences of Polypharmacy in Elderly. Expert Opin Drug Saf 2014;13

26. Kim KJ, Shin J, Choi J, Park JM, Park HK, Lee J, Han SH. Association of Geriatric Syndromes with Urinary Incontinence according to Sex and UrinaryIncontinence-Related Quality of Life in Older Inpatients: A Cross-Sectional Study of an Acute Care Hospital. Korean J Fam Med 2019;40:235-240.

27. Schneidinger CS, Umek W, Böhmdorfer B. The Problem of Polypharmacy in Female Patients with Overactive Bladders - Cross-Sectional Study in a Specialist Outpatient Department. Geburtshilfe Frauenheilkd 2016;76:1318-1324. 